\title{
Healthcare Professionals' Perceptions of Type 2 Diabetes Mellitus Care in the Mediterranean Region
}

\author{
Charles Savona-Ventura (D) - Josanne Vassallo on behalf of the MGSD-Education Study Group
}

Received: July 5, 2019 / Published online: July 31, 2019

(C) The Author(s) 2019

\section{ABSTRACT}

Introduction: This study aimed to assess the adherence to guidelines by practitioners working in the Mediterranean region and to identify the reasons for non-compliance.

Methods: A opportunistic self-administered questionnaire was circulated among members of the Mediterranean Group for the Study of Diabetes (MGSD) and regional diabetic associations. The study was limited to the Mediterranean region; 2841 medical practitioners participated in the study. Intervention involved a self-administered questionnaire enabling demographic and personal details to be correlated to relevant information related to practice

The members of the MGSD-Education Study Group are listed in Acknowledgements.

Enhanced Digital Features To view enhanced digital features for this article go to https://doi.org/10.6084/ m9.figshare.8976458.

Electronic Supplementary Material The online version of this article (https://doi.org/10.1007/s13300019-00675-2) contains supplementary material, which is available to authorized users.

C. Savona-Ventura $(\bowtie)$

Department of Obstetrics and Gynaecology, University of Malta, Tal-Qroqq, Msida, Malta e-mail: charles.savona-ventura@um.edu.mt

J. Vassallo

Department of Medicine, University of Malta,

Tal-Qroqq, Msida, Malta and continuing health professional education (CHPE) attitudes, perceptions related to diabetes and healthcare systems in the community, and physicians' attitudes to healthcare practices and target goals relevant to type 2 diabetes mellitus (T2DM). The main outcome measure was adherence to evidence-based guidelines.

Results: While the majority of respondents (69.9\%) reported being confident in managing these patients, and $79.2 \%$ reported being aware of the availability of local guidelines; only a fifth opted to manage patients by strictly targeting an HbA1c value below $6.5 \%$, while $3.3 \%$ were happy to maintain an HbA1c value of up to $8.0 \%$. These goals appeared to be tempered by fear of eliciting hypoglycaemia in the belief that patients and their families do not have the skills to manage the complication. Endocrinologists/internists preferred more rigid control.

Conclusion: It is clear that the promulgation of evidence-based guidelines cannot assume automatic adoption in clinical practice since adoption is tempered by on-the-ground practice circumstances that make the practitioner reluctant to fully endorse and adopt the targets defined by the guidelines. The evidence-based guidelines need to be modified for local or regional circumstances.

Funding: This study and the Rapid Service Fee were supported by a financial grant from the Mediterranean Group for the Study of Diabetes which is supported by an unrestricted 
educational grant from Servier.Keywords: Diabetes mellitus; Guideline adherence; Health personnel; Mediterranean region; Patient care; Type 2

\section{INTRODUCTION}

Continuing health professional education (CHPE) is an essential prerequisite for providing up-to-date evidence-based clinical care since advancement in medical thought and therapeutics is a progressive process that moves forward at a steady often rapid rate. This premise is even more telling in diabetes mellitus management since various factors have played a role in changing management options and targets. These have included the development of new pharmaceutical agents, identification of optimum biochemical targets based on clinical target outcomes, and involvement of different stakeholders at different levels of disease management including the changing attitudes towards principles of patient empowerment. These advances have led to the promulgation of clinical guidelines that serve to guide clinicians to thus strive to provide the best care with the primary aim of reducing long-term complications with best quality of life. The design and publication of these evidence-based clinical guidelines is not enough to ensure that patient care is positively influenced. These guidelines must be circulated to the medical practitioner on the ground and modified according to the healthcare provisions available in the various different communities.

The Mediterranean region represents a unique regional setting with common ethnic and cultural features, but definitely heterogeneous in terms of socio-economic, political and demographical factors. These sociopolitical differences result in varying levels of healthcare provision and education facilities especially as these relate to community care services. These differences influence the attitudes of healthcare providers towards healthcare practices in respect to patient care and empowerment. These in turn determine how the healthcare providers look upon established evidence-based standard guidelines and their willingness to adhere to these. These healthcare differences are particularly marked between the countries bordering the northern bank and those bordering the southern bank of the Mediterranean Sea. There are also differences in healthcare practices between the countries bordering the western part and the eastern part of the northern bank. Standard guidelines must therefore be tempered to local needs and available facilities, besides the views and perceptions of healthcare professionals towards type 2 diabetes mellitus (T2DM) care. Awareness of these views and perceptions is an essential prerequisite prior to undertaking any CHPE programme.

The present study was undertaken by the Mediterranean Group for the Study of Diabetes (MGSD) to assess the views and perceptions towards T2DM care of primary and hospital-based healthcare professionals, and members of professional bodies and their trainees in the Mediterranean region as this relates to practice organization, clinical issues relating to diagnosis and complications, attitudes to diabetes control, and the use of clinical guidelines including recommended targets of control. The MGSD was set up in 1985 to meet the needs of all those health professionals in the Mediterranean area involved in the delivery of diabetes care. The MGSD aims to bring together health professionals from a widely different socially and educationally heterogeneous region to keep them abreast of the latest key developments in the specialty and to establish training programmes empowering those entering the specialty with the requisite technical skills to conduct broad national studies. The information would thus serve to provide a diagnostic educational baseline picture which would allow tailored training programmes to be designed for the region.

\section{METHODS}

The study was carried out using a self-administered questionnaire using either an electronic version hosted on the website of the MGSD with a dedicated domain address or a hard-copy format questionnaire distributed during relevant regional or national academic meetings. To 
ensure as wide a distribution as possible, all relevant professional associations in the various countries in the Mediterranean region were asked to circulate a notice to their members inviting them to participate in the study. The study population was therefore an opportunistic population. The questionnaire was compiled and designed by the members of the MGSD Educational Study Group representing all three regions of the Mediterranean to ensure that the language used was clearly understandable. The questionnaire design also took into consideration the potential multitude of worldwide guidelines relating to T2DM that the respondents may be familiar with. The questionnaire therefore avoided referring to specific guidelines but set outcome glycaemic level preferences, notably glycosylated haemoglobin (HbA1c). During analysis of the responses, an HBA1c level below $7.0 \%$ was taken as a desirable target as defined by most, though not necessarily all, published guidelines. Besides information relating to demographic details, the questionnaire further collected information related to practice and CHPE attitudes, perceptions related to diabetes and healthcare systems in the community, and physicians' attitudes to healthcare practices and target goals relevant to T2DM. Since the questionnaire was a self-administered one completed on a voluntary basis and not including any sensitive personal or identifiable information, the study was exempted from formal ethical approval by the University of Malta Research Ethics Committee. Statistics used were mainly descriptive. Inferential relationships were tested whenever appropriate using the chi-square test.

A total of 3048 physicians participated in the study; of these 207 were excluded since they failed to provide their country of residence or resided outside the Mediterranean region. Respondents were divided into three groups: (a) those from the southern bank of the Mediterranean region including countries in the Northern Africa or Maghreb region numbered 849; (b) respondents from the western region of the northern bank numbered 607, representing respondents mainly from the Iberian Peninsula incorporating Spain and Portugal, and Malta; and (c) respondents from the eastern region of the northern bank numbered 1385 , representing mainly Greece, Serbia and Lebanon.

\section{RESULTS}

The overall study population showed a particular bias to females with a male-to-female ratio of 0.78 and to individuals employed in the public sector with a public-to-private sector ratio of 4.22 , with $49.9 \%$ of respondents working in a hospital environment and $38.8 \%$ in the primary health sector. Only $14.1 \%$ classified their specialty as that of an endocrinologist/diabetologist, while $44.1 \%$ and $23.4 \%$ identified themselves as cardiologists/internists and family doctors respectively. The large majority had qualified less than 20 years previously. A significant majority relied on academic meetings, published material and web-based sources for their CHPE (Table 1). There were noted differences in the characteristics of the respondents between the three regions. The respondents from the southern bank region were more likely to be employed as internists/cardiologists in university hospitals. The western region respondents were more likely to belong to the male gender, be more professionally mature and were more likely to be working as primary health physicians. The respondents in the eastern region were more likely to be employed in the public primary healthcare sector but were more likely to be represented by internists/cardiologists. Diabetologists/endocrinologists accounted for 23.3\%, $25.0 \%$ and $4.3 \%$ respectively. There was very little difference in how the respondents preferred to continue their professional development, the large majority preferring to rely on journals and textbooks, academic meetings and web-based sources (Table 1).

A large proportion of respondents (69.9\%) were confident or very confident in their overall capability of managing patients with T2DM in their practice irrespective of the fact that there were marked variations in the support services available to them (Table 2). Public health support systems were generally considered to be adequately available (75.0\%) with availability of a good follow-up system (64.1\%). Team 
Table 1 Population characteristics (differences in totals due to unanswered responses)

\begin{tabular}{|c|c|c|c|c|c|c|c|c|}
\hline \multirow{2}{*}{$\begin{array}{l}\text { Population characteristics } \\
\text { Gender ratio (male/female) }\end{array}$} & \multicolumn{2}{|c|}{$\begin{array}{l}\text { Southern bank } \\
N=849\end{array}$} & \multicolumn{2}{|c|}{$\begin{array}{l}\text { Northwestern } \\
N=\mathbf{6 0 7}\end{array}$} & \multicolumn{2}{|c|}{$\begin{array}{l}\text { Northeastern } \\
N=1385\end{array}$} & \multicolumn{2}{|c|}{$\begin{array}{l}\text { Total study population } \\
N=2841\end{array}$} \\
\hline & 0.80 & & 1.03 & & 0.67 & & 0.78 & \\
\hline Public/private ratio & 3.18 & & 3.59 & & 5.63 & & 4.22 & \\
\hline \multicolumn{9}{|l|}{ Place of work } \\
\hline General hospital & 202 & $24.7 \%$ & 141 & $23.8 \%$ & 269 & $19.8 \%$ & 612 & $21.5 \%$ \\
\hline University hospital & 340 & $41.5 \%$ & 162 & $27.3 \%$ & 304 & $22.4 \%$ & 806 & $28.4 \%$ \\
\hline Primary health & 181 & $22.1 \%$ & 220 & $37.1 \%$ & 701 & $51.7 \%$ & 1102 & $38.8 \%$ \\
\hline Other & 96 & $11.7 \%$ & 70 & $11.8 \%$ & 83 & $6.1 \%$ & 249 & $8.8 \%$ \\
\hline \multicolumn{9}{|l|}{ Speciality } \\
\hline Cardiologist/internist & 379 & $46.7 \%$ & 159 & $26.3 \%$ & 714 & $51.6 \%$ & 1252 & $44.1 \%$ \\
\hline Diabetologist/endocrinologist & 189 & $23.3 \%$ & 151 & $25.0 \%$ & 60 & $4.3 \%$ & 400 & $14.1 \%$ \\
\hline Primary health physician & 90 & $11.1 \%$ & 258 & $42.6 \%$ & 316 & $22.8 \%$ & 664 & $23.4 \%$ \\
\hline Other & 154 & $18.9 \%$ & 37 & $6.1 \%$ & 294 & $21.2 \%$ & 485 & $17.1 \%$ \\
\hline \multicolumn{9}{|l|}{ Years since qualification } \\
\hline$\geq 20$ years & 277 & $37.6 \%$ & 408 & $69.6 \%$ & 543 & $40.7 \%$ & 1228 & $43.3 \%$ \\
\hline \multicolumn{9}{|l|}{ CHPE } \\
\hline Journals and textbooks & 435 & $51.8 \%$ & 273 & $45.0 \%$ & 599 & $43.2 \%$ & 1307 & $46.0 \%$ \\
\hline Academic meetings & 447 & $53.2 \%$ & 351 & $57.8 \%$ & 905 & $65.3 \%$ & 1703 & $59.9 \%$ \\
\hline Advertisements & 189 & $22.5 \%$ & 175 & $28.8 \%$ & 382 & $27.6 \%$ & 746 & $26.3 \%$ \\
\hline Web-based sources & 423 & $50.4 \%$ & 293 & $48.3 \%$ & 605 & $43.7 \%$ & 1321 & $46.5 \%$ \\
\hline Other & 32 & $3.8 \%$ & 51 & $8.4 \%$ & 61 & $4.4 \%$ & 144 & $5.1 \%$ \\
\hline
\end{tabular}

management and patient education services were less widely available $(53.7 \%$ and $55.6 \%$ respectively). Specialist follow-up services to assess ophthalmic and vascular complications were considered adequately available by $76.1 \%$ and $74.4 \%$ respectively. A lower proportion were happy with follow-up services related to neurological and nephrological complications (57.8\% and $69.1 \%$ respectively). More than $80 \%$ of respondents believed in patient self-empowerment discussing management plans and management goals with their patients and promoting self-monitoring of blood glucose; however, only $61.4 \%$ encouraged treatment self-modification by patients (Table 2 ). There were marked variations in support services across the different regions. While the northwestern region reported very good support services being available to supplement their practice as compared to the northeastern and southern regions, the reported confidence rates were similar $(74 \%$ vs $66 \%$ and $75 \%$ respectively). Patient empowerment appeared to be highest in the northeastern region with a good proportion of practitioners reporting discussing treatment goals $(90.2 \%)$, negotiating a management plan with the patient (84.1\%), encouraging blood glucose self-monitoring $(91.5 \%)$, and encouraging self-modification of the treatment $(74.7 \%)$. The two other regions 
Table 2 Practice characteristics and services (differences in totals due to unanswered responses)

\begin{tabular}{|c|c|c|c|c|c|c|c|c|}
\hline \multirow{2}{*}{$\begin{array}{l}\text { Population characteristics } \\
\text { Management confidence }\end{array}$} & \multicolumn{2}{|c|}{$\begin{array}{l}\text { Southern bank } \\
N=849\end{array}$} & \multicolumn{2}{|c|}{$\begin{array}{l}\text { Northwestern } \\
N=607\end{array}$} & \multicolumn{2}{|c|}{$\begin{array}{l}\text { Northeastern } \\
N=1385\end{array}$} & \multicolumn{2}{|c|}{$\begin{array}{l}\text { Total study population } \\
N=2841\end{array}$} \\
\hline & & & & & & & & \\
\hline Not confident & 24 & $2.9 \%$ & 20 & $3.3 \%$ & 68 & $4.9 \%$ & 112 & $3.9 \%$ \\
\hline Somewhat not confident & 183 & $22.1 \%$ & 136 & $22.7 \%$ & 386 & $28.1 \%$ & 705 & $24.8 \%$ \\
\hline Confident & 447 & $53.9 \%$ & 294 & $49.0 \%$ & 654 & $47.6 \%$ & 1395 & $49.1 \%$ \\
\hline Very confident & 175 & $21.1 \%$ & 150 & $25.0 \%$ & 266 & $19.4 \%$ & 591 & $20.8 \%$ \\
\hline \multicolumn{9}{|c|}{ Health care facilities for T2DM patients } \\
\hline Public healthcare support & 492 & $58.0 \%$ & 518 & $85.3 \%$ & 1120 & $80.9 \%$ & 2130 & $75.0 \%$ \\
\hline Patient educational support & 423 & $49.9 \%$ & 465 & $76.6 \%$ & 693 & $50.1 \%$ & 1581 & $55.6 \%$ \\
\hline Team management services & 357 & $42.1 \%$ & 469 & $77.3 \%$ & 700 & $50.6 \%$ & 1526 & $53.7 \%$ \\
\hline Availability of follow-up & 480 & $56.6 \%$ & 572 & $94.2 \%$ & 769 & $55.6 \%$ & 1821 & $64.1 \%$ \\
\hline \multicolumn{9}{|l|}{ Easy availability of facilities } \\
\hline Ophthalmic services & 609 & $71.8 \%$ & 548 & $90.3 \%$ & 1005 & $72.6 \%$ & 2162 & $76.1 \%$ \\
\hline Nephrology services & 588 & $69.3 \%$ & 533 & $87.8 \%$ & 822 & $59.4 \%$ & 1963 & $69.1 \%$ \\
\hline Neurological & 453 & $53.4 \%$ & 502 & $82.7 \%$ & 687 & $49.6 \%$ & 1642 & $57.8 \%$ \\
\hline Cardiovascular & 563 & $66.4 \%$ & 486 & $80.1 \%$ & 1066 & $77.0 \%$ & 2115 & $74.4 \%$ \\
\hline \multicolumn{9}{|l|}{ T2DM patient empowerment } \\
\hline Negotiation of management & 625 & $73.7 \%$ & 523 & $86.2 \%$ & 1164 & $84.1 \%$ & 2312 & $81.4 \%$ \\
\hline Discuss treatment goals & 710 & $83.7 \%$ & 492 & $81.1 \%$ & 1248 & $90.2 \%$ & 2450 & $86.2 \%$ \\
\hline Encourage self-monitoring & 648 & $76.4 \%$ & 448 & $73.8 \%$ & 1267 & $91.5 \%$ & 2363 & $83.2 \%$ \\
\hline Treatment self-modification & 434 & $51.2 \%$ & 276 & $45.5 \%$ & 1034 & $74.7 \%$ & 1744 & $61.4 \%$ \\
\hline
\end{tabular}

reported lower rates of patient empowerment practices (Table 2).

Confidence in capability to manage adequately T2DM patients was statistically dependent on the specialty the practitioner belonged to, with diabetologists/endocrinologists reportedly being more confident in their management regimens. Practitioners from the eastern region reported being less confident in the management of these patients. There appeared to be no statistical relationship between confidence and the awareness of local guidelines availability, attitudes towards patient empowerment, and acceptable glycosylated haemoglobin (HbA1c) targets (Table 3). There were differences between the different regions. Physicians from the southern region were very likely not to be aware of the availability of local guidelines compared to those from the north. Diagnostic criteria for T2DM were generally based on the estimation of a fasting blood glucose with HbA1c being more likely used to supplement the diagnosis in the northwestern doctors who were less likely to resort to a formal oral glucose tolerance test (oGTT). The northeastern practitioners were more likely to resort to an oGTT to establish the diagnosis. Just over $50 \%$ of the respondents in all the regions believed that it was essential to maintain optimum blood glucose level but only about a fifth of the 
Table 3 Practice confidence relationships (differences in totals due to unanswered responses)

\begin{tabular}{|c|c|c|c|c|c|}
\hline \multirow[t]{2}{*}{ Practice confidence relationships } & \multicolumn{2}{|c|}{$\begin{array}{l}\text { Confident } \\
N=1985\end{array}$} & \multicolumn{2}{|c|}{$\begin{array}{l}\text { Not confident } \\
N=817\end{array}$} & \multirow[t]{2}{*}{$P$ value } \\
\hline & No. & $\%$ & No. & $\%$ & \\
\hline \multicolumn{6}{|l|}{ Region } \\
\hline Northwestern region & 444 & 22.4 & 156 & 19.1 & \multirow[t]{3}{*}{0.055} \\
\hline Southern bank region & 621 & 31.3 & 207 & 25.3 & \\
\hline Northeastern region & 920 & 46.3 & 454 & 55.6 & \\
\hline \multicolumn{6}{|l|}{ Specialty } \\
\hline Cardiologist & 73 & 3.7 & 32 & 3.9 & \multirow[t]{5}{*}{0.0001} \\
\hline Diabetologist/endocrinologist & 317 & 16.3 & 79 & 9.7 & \\
\hline Internist & 800 & 41.0 & 332 & 40.9 & \\
\hline Primary health physician & 434 & 22.3 & 215 & 26.5 & \\
\hline Other specialty & 326 & 16.7 & 154 & 19.0 & \\
\hline \multicolumn{6}{|l|}{ Optimal target $\mathrm{HbAlc}$} \\
\hline$<6.5 \%$-very stringent control & 408 & 20.9 & 182 & 22.5 & \multirow[t]{4}{*}{0.11} \\
\hline$<7.0 \%$ & 1311 & 67.1 & 556 & 68.6 & \\
\hline$<7.5 \%$ & 171 & 8.8 & 53 & 6.5 & \\
\hline$<8.0 \%$-less stringent control & 64 & 3.3 & 19 & 2.3 & \\
\hline \multicolumn{6}{|c|}{ Knowledge about availability of national guidelines } \\
\hline Aware of availability & 1569 & 79.4 & 653 & 80.1 & \multirow[t]{2}{*}{0.73} \\
\hline Unaware of availability & 406 & 20.6 & 162 & 19.9 & \\
\hline \multicolumn{6}{|l|}{ Patient empowerment to adjust dosage } \\
\hline Promotes empowerment & 1211 & 61.8 & 518 & 64.1 & \multirow[t]{2}{*}{0.27} \\
\hline Discourages empowerment & 749 & 38.2 & 290 & 35.9 & \\
\hline
\end{tabular}

respondents opted for very strict $\mathrm{HbA} 1 \mathrm{c}$ control at a level below $6.5 \%$ with the larger majority preferring an HbA1c level below 7.0\% (Table 3). These management goals appeared to be tempered by a fear of eliciting hypoglycaemia with practitioners generally believing that the patients and their families do not have the required skills to manage the complication (Table 4).

Overall, $79.2 \%$ of practitioners were aware of the availability of local guidelines. The majority relied on a fasting blood glucose estimation to diagnose the condition with $62.4 \%$ and $44.8 \%$ resorting to an HbA1c estimation and oral glucose tolerance test respectively. Over 50\% of the respondents believed that it was essential to maintain optimum blood glucose level but only about a fifth of the respondents opted for very strict HbA1c control at a level below 6.5\% with the larger majority preferring an HbA1c level below $7.0 \%$. However, $3.3 \%$ of the respondents were happy with an HbA1c target of up to $8.0 \%$ (Table 4). The management target goals were very much dependent on the specialty of the 
Table 4 Target goals attitudes (differences in totals due to unanswered responses)

\begin{tabular}{|c|c|c|c|c|c|c|c|c|}
\hline \multirow{2}{*}{$\begin{array}{l}\text { Target goals attitudes } \\
\text { Physician awareness of local guidelines }\end{array}$} & \multicolumn{2}{|c|}{$\begin{array}{l}\text { Southern } \\
\text { bank } \\
N=849\end{array}$} & \multicolumn{2}{|c|}{$\begin{array}{l}\text { Northwestern } \\
N=607\end{array}$} & \multicolumn{2}{|c|}{$\begin{array}{l}\text { Northeastern } \\
N=1385\end{array}$} & \multicolumn{2}{|c|}{$\begin{array}{l}\text { Total study } \\
\text { population } \\
N=2841\end{array}$} \\
\hline & 502 & $59.2 \%$ & 513 & $84.5 \%$ & 1235 & $89.2 \%$ & 2250 & $79.2 \%$ \\
\hline \multicolumn{9}{|l|}{ Diagnostic criteria for T2DM } \\
\hline Fasting blood glucose & 723 & $85.2 \%$ & 507 & $83.5 \%$ & 1187 & $85.7 \%$ & 2417 & $85.1 \%$ \\
\hline Oral glucose tolerance test & 272 & $32.0 \%$ & 109 & $18.0 \%$ & 891 & $64.3 \%$ & 1272 & $44.8 \%$ \\
\hline HbAlc & 532 & $62.7 \%$ & 465 & $76.6 \%$ & 777 & $56.1 \%$ & 1774 & $62.4 \%$ \\
\hline \multicolumn{9}{|l|}{ Target goals } \\
\hline Ideal BG essential target & 497 & $58.5 \%$ & 357 & $58.8 \%$ & 706 & $51.0 \%$ & 1560 & $54.9 \%$ \\
\hline \multicolumn{9}{|l|}{ Optimal target $\mathrm{HbAlc}$} \\
\hline$<6.5 \%$-very stringent & 176 & $21.7 \%$ & 115 & $18.9 \%$ & 303 & $22.0 \%$ & 594 & $20.9 \%$ \\
\hline$<7.0 \%$ & 663 & $81.7 \%$ & 525 & $86.5 \%$ & 1285 & $93.3 \%$ & 2473 & $87.0 \%$ \\
\hline$<7.5 \%$ & 782 & $96.3 \%$ & 574 & $94.6 \%$ & 1346 & $97.7 \%$ & 2702 & $95.1 \%$ \\
\hline$<8.0 \%$-less stringent & 810 & $100.0 \%$ & 607 & $100.0 \%$ & 1378 & $100.0 \%$ & 2795 & $98.4 \%$ \\
\hline \multicolumn{9}{|l|}{ Attitudes towards hypoglycaemia } \\
\hline $\begin{array}{l}\text { Hypoglycaemia common enough to influence } \\
\text { management choices }\end{array}$ & 591 & $69.6 \%$ & 394 & $64.9 \%$ & 1136 & $82.0 \%$ & 2121 & $74.7 \%$ \\
\hline $\begin{array}{l}\text { Treatment modification necessary if BG } 3.5-4.0 \mathrm{mmol} / \mathrm{l} \\
\text { irrespective of symptomatology }\end{array}$ & 626 & $73.7 \%$ & 476 & $78.4 \%$ & 871 & $62.9 \%$ & 1973 & $69.4 \%$ \\
\hline $\begin{array}{l}\text { Family/patient competences re hypoglycaemia } \\
\text { management }\end{array}$ & 634 & $74.8 \%$ & 531 & $87.5 \%$ & 1021 & $73.8 \%$ & 2186 & $76.9 \%$ \\
\hline
\end{tabular}

practitioner. It therefore would appear that a greater proportion of diabetologists/endocrinologists and internists/cardiologists preferred a target HbA1c goal of below 7.0\% when compared to primary health physicians and other specialties (Table 5).

The metformin add-on medication in case of monotherapy failure was generally one of the sulfonylureas or meglitinide group with dipeptidyl peptidase 4 (DPP-4) inhibitors being increasingly used. Insulin was reported to be the favoured add-on medication choice by $7.0 \%$ of respondents, even though $58.2 \%$ of respondents reported encountering difficulties with introducing insulin in the therapeutic regimen generally because of patient reluctance (Table 6).

In respect to management of T2DM and gestational diabetes (GDM) during pregnancy, the respondents were generally (70.6\%) aware of the services of pre-conception care services for T2DM patients who desire to conceive. Respondents in the southern region were more likely to be unaware of the availability of preconception care services. Oral glucose-lowering medications were only being resorted to for the management of pregnant women by less than a quarter of the respondents, while about $60 \%$ were happy to use insulin analogues during pregnancy. Oral hypoglycaemic pharmaceuticals were more likely to be resorted to in 
Table 5 Target HbAlc by specialty (differences in totals due to unanswered responses)

\begin{tabular}{|c|c|c|c|c|c|}
\hline \multirow[t]{2}{*}{ HbA1c level target } & \multicolumn{2}{|c|}{$<7.0 \%$} & \multicolumn{2}{|c|}{$>7.0 \%$} & \multirow[t]{2}{*}{$P$ value } \\
\hline & No. & $\%$ & No. & $\%$ & \\
\hline Diabetologist/endocrinologist & 355 & 14.5 & 36 & 11.4 & \\
\hline Internist/cardiologist & 1108 & 45.4 & 122 & 38.6 & \\
\hline Primary health physician & 539 & 22.1 & 101 & 32.0 & \\
\hline Other & 439 & 18.0 & 57 & 18.0 & 0.01 \\
\hline
\end{tabular}

Table 6 Treatment choices attitudes (differences in totals due to unanswered responses)

\begin{tabular}{|c|c|c|c|c|c|c|c|c|}
\hline Treatment choices & \multicolumn{2}{|c|}{$\begin{array}{l}\text { Southern } \\
\text { bank } \\
N=849\end{array}$} & \multicolumn{2}{|c|}{$\begin{array}{l}\text { Northwestern } \\
N=607\end{array}$} & \multicolumn{2}{|c|}{$\begin{array}{l}\text { Northeastern } \\
N=1385\end{array}$} & \multicolumn{2}{|c|}{$\begin{array}{l}\text { Total study } \\
\text { population } \\
N=2841\end{array}$} \\
\hline \multicolumn{9}{|c|}{ What is your most common choice as add-on therapy in case of metformin monotherapy failure? } \\
\hline Sulfonylureas/meglitinides & 543 & $64.0 \%$ & 244 & $40.2 \%$ & 747 & $53.9 \%$ & 1534 & $54.0 \%$ \\
\hline DPP-4 inhibitors & 76 & $9.0 \%$ & 302 & $49.8 \%$ & 469 & $33.9 \%$ & 847 & $29.8 \%$ \\
\hline Thiazolidinediones & 8 & $0.9 \%$ & 6 & $1.0 \%$ & 25 & $1.8 \%$ & 39 & $1.4 \%$ \\
\hline GLP-1 receptor agonists & 11 & $1.3 \%$ & 29 & $4.8 \%$ & 37 & $2.7 \%$ & 77 & $2.7 \%$ \\
\hline SGLT-2 inhibitors & 9 & $1.1 \%$ & 13 & $2.1 \%$ & 7 & $0.5 \%$ & 29 & $1.0 \%$ \\
\hline Acarbose & 15 & $1.8 \%$ & 2 & $0.3 \%$ & 4 & $0.3 \%$ & 21 & $0.7 \%$ \\
\hline Insulin & 98 & $11.5 \%$ & 8 & $1.3 \%$ & 92 & $6.6 \%$ & 198 & $7.0 \%$ \\
\hline $\begin{array}{l}\text { Do you have difficulties in starting insulin treatment in } \\
\text { patients with T2DM when other management options } \\
\text { fail to control glycaemia? }\end{array}$ & 593 & $30.9 \%$ & 204 & $33.6 \%$ & 857 & $61.9 \%$ & 1654 & $58.2 \%$ \\
\hline \multicolumn{9}{|l|}{ Why? } \\
\hline Insufficient experience & 183 & $30.9 \%$ & 37 & $18.1 \%$ & 337 & $39.3 \%$ & 557 & $19.6 \%$ \\
\hline Patient reluctance/difficulties & 328 & $53.3 \%$ & 14 & $70.1 \%$ & 490 & $57.2 \%$ & 832 & $29.3 \%$ \\
\hline Fear of hypoglycaemia & 186 & $31.4 \%$ & 45 & $22.1 \%$ & 223 & $26.0 \%$ & 454 & $16.0 \%$ \\
\hline Other reason $/ \mathrm{s}$ & 75 & $12.6 \%$ & 7 & $3.4 \%$ & 120 & $14.0 \%$ & 202 & $7.1 \%$ \\
\hline
\end{tabular}

pregnant women in the northwestern region than their counterparts in the other regions, while practitioners from the southern region appeared more likely to resort to insulin analogues during pregnancy than their counterparts in the other regions especially in the northeastern region. About a fifth of the respondents reported that they still use the old
1999 World Health Organization (WHO) oGTT diagnostic criteria to identify women with GDM. Less than a fifth of the respondents had adopted the criteria adopted by the International Associations for Diabetes in Pregnancy Study Groups (IADPSG) to establish a diagnosis of GDM. The larger majority rely of the American Diabetes Association (ADA) or the IADPSG 
criteria to establish a diagnosis with the IADPSG being the less likely criteria used by northwestern practitioners (Table 7).

\section{DISCUSSION}

The formulation of practice guidelines is the natural follow-up to the goal of implementing evidence-based practice. Many developed countries have set out to standardize practice by publishing guidelines for virtually all aspects of healthcare. Many of these guidelines have been adopted by the Guidelines International Network [1]. Evidence-based practice guidelines for the management for type 2 diabetes mellitus have been developed with the aim of reducing the long-term morbidity of the condition [2-4]. These have been further abridged to address the needs of the busy primary healthcare provider [5]. Compliance with evidence-based guidelines seems to be problematic since the development of these seems to have had little impact on actual primary care practices [6]. A study carried out in Norway to assess the physicians' adherence to clinical guidelines by reviewing patient files showed that more than half of the patients aged less than 70 years had HbA1c levels above the recommended level. Similarly, attention to the control of the systolic blood pressure did not reach target levels [7]. The reasons as to why practitioners fail to rigorously follow the published guidelines are varied, ranging from lack of familiarity with updated guidelines to inability to apply them with the community they serve $[8,9]$. More studies relating to sustainability of adherence to clinical guideline by healthcare professionals are needed to assess why adherence to guidelines principles is not sustained over the long term. This study population was an opportunistic population and may therefore carry particular biases and cannot truly be said to be a totally representative sample, being biased by interest and opportunity to answering the questionnaire presented. However, important and relevant observations have been identified.

This study has shown that a fifth of the respondents were not aware of any practice guidelines related to T2DM care, though this did not appear to influence the practitioners' confidence in managing the patients. As expected, confidence in managing T2DM patients was more prevalent in endocrinologists or diabetologists rather that the other specialties particularly family medicine practitioners. These observations are a reflection of acquired knowledge and awareness of the defined evidence-based clinical practice.

Table 7 Management attitudes in pregnant women (differences in totals due to unanswered responses)

\begin{tabular}{llrrrrrrr}
\hline Pregnancy management & $\begin{array}{l}\text { Southern } \\
\text { bank } \\
\boldsymbol{N}=\mathbf{8 4 9}\end{array}$ & $\begin{array}{l}\text { Northwestern } \\
\boldsymbol{N}=\mathbf{6 0 7}\end{array}$ & $\begin{array}{l}\text { Northeastern } \\
\boldsymbol{N}=\mathbf{1 3 8 5}\end{array}$ & $\begin{array}{l}\text { Total study } \\
\text { population } \\
\boldsymbol{N}=\mathbf{2 8 4 1}\end{array}$ \\
\hline Availability of pre-conception care facilities & 506 & $59.6 \%$ & 490 & $80.7 \%$ & 1010 & $72.9 \%$ & 2006 & $70.6 \%$ \\
Use oral hypoglycaemic agents during pregnancy in GDM & 156 & $18.4 \%$ & 208 & $34.3 \%$ & 271 & $19.6 \%$ & 635 & $22.4 \%$ \\
Use insulin analogues during pregnancy in GDM & 624 & $73.5 \%$ & 377 & $62.1 \%$ & 680 & $49.1 \%$ & 1681 & $59.2 \%$ \\
Diagnostic criteria for GDM used & & & & & & & & \\
WHO (old) & 182 & $21.4 \%$ & 107 & $17.6 \%$ & 332 & $24.0 \%$ & 621 & $21.9 \%$ \\
ADA & 189 & $22.3 \%$ & 152 & $25.0 \%$ & 192 & $13.9 \%$ & 533 & $18.8 \%$ \\
IADPSG & 171 & $20.1 \%$ & 75 & $12.4 \%$ & 288 & $20.8 \%$ & 534 & $18.8 \%$ \\
Other & 43 & $5.1 \%$ & 114 & $18.8 \%$ & 28 & $2.0 \%$ & 185 & $6.5 \%$ \\
Referral + unrecorded & 314 & $37.0 \%$ & 157 & $25.9 \%$ & 582 & $42.0 \%$ & 1053 & $37.1 \%$ \\
\hline
\end{tabular}


Continuing professional educational programmes need to be organized by the responsible professional bodies to ensure that professionals-whatever the specialty-are made aware of the standard guidelines [10]. The modern professional media must be utilized fully to disseminate these guidelines. In spite of the relatively mature respondent population in the study, about half reported relying on webbased information sources to update their knowledge.

Another important determinant detracting from the adoption of evidence-based clinical guidelines is the view that these guidelines are simply designed for use in a developed country with good support services in a highly educated population. Such practices may be perceived as unattainable because of lack of resources or because of potential associated adverse consequences such as hypoglycaemia. While the present study did not investigate all the potential contributors to non-adherence to guideline protocols, T2DM patient characteristics such as the expected short life expectancy and presence of comorbidities may also influence the practitioners' tendency towards non-adherence. These are relevant concerns and dedicated practice guidelines need to be formulated for specific populations, balancing ideal management with practicality on the basis of available resources and support services. Only in this way can practitioners working in relative isolation be encouraged to provide the best ideal management plan in the context of their environment. In this study, family doctor practitioners were proportionately more likely to accept a glycosylated haemoglobin level higher than proposed by evidence-based guidelines. The main detractor to adopting stringent targets for HbA1c appears to be the fear of inducing hypoglycaemia in patients, with over $58 \%$ of respondents reporting that problems were encountered when attempting to introduce insulin in the therapeutic regimen and 16\% quoting fear of inducing hypoglycaemia as the deterrent. This may potentially be a reflection that these practitioners deal with patients with different profiles than the hospital-based physician. About $20 \%$ of respondents reported, however, that their reluctance to introduce insulin in the therapeutic regimen was the result of insufficient professional experience. This emphasizes the need for continuous professional education to ensure that practitioners are knowledgeable and skilled in how and when to initiate insulin add-on treatment and how to monitor the patient to ensure management within a safety profile. The practitioners also need to be made increasingly familiar with the management of hypogylcaemia but, more importantly, they need to be motivated to empower the patient and close family to be better equipped to manage this complication of adding on insulin to the therapeutic regimen [11]. About $80 \%$ of respondents were unhappy with the perceived level of competence in patients and family in managing hypoglycaemia [12].

In respect to gestational diabetes management, in spite of updated diagnostic criteria based on evidence-based outcome indicators, there appears to be continuing non-conformity of the diagnostic criteria to diagnose GDM, with less than $20 \%$ relying on the currently recommended IADPSG criteria. About $40 \%$ are still relying on past criteria. The adoption of standard uniform criteria is essential to ensure conformity with evidence-based guidelines and to enable comparisons of management outcomes between communities and countries. While the current guidelines still promote the use of insulin in managing GDM because of concerns regarding potential long-term effects of oral hypoglycaemic agents on the foetus, there is still a role for these agents especially in environments where close monitoring or where patient compliance may be an issue. Only about a quarter of respondents actually reported incorporating oral hypoglycaemic agents as part of their therapeutic armamentarium in the management of GDM. In contrast about $60 \%$ of respondents were willing to use insulin analogues in the management of GDM.

\section{CONCLUSION}

It is clear that the promulgation of evidencebased guidelines cannot assume automatic compliance. The adoption of these guidelines in 
clinical practice is tempered by communication issues that delay the information from reaching the practitioner on the ground and by on-theground practice circumstances that make the practitioner reluctant to fully endorse and adopt the targets defined by the guidelines. The evidence-based guidelines need to be modified by the local or regional professional bodies to suit the local circumstances; these modified guidelines then need to be actively distributed to all practitioners involved with the care of T2DM patients.

\section{ACKNOWLEDGEMENTS}

We thank the IT and country representative staff of Servier who assisted with the setting up of the internet-based questionnaire and the distribution of hard copies of the questionnaire in various countries. We further thank all the participants of the study.

Funding. This study and the Rapid Service Fee were supported by a financial grant from the Mediterranean Group for the Study of Diabetes which is supported by an unrestricted educational grant from Servier. All authors had full access to all of the data in this study and take complete responsibility for the integrity of the data and accuracy of the data analysis.

Authorship. All named authors meet the International Committee of Medical Journal Editors (ICMJE) criteria for authorship for this article, take responsibility for the integrity of the work as a whole, and have given their approval for this version to be published.

Authorship Contributions. The primary authors of the paper are the guarantors of the study taking full responsibility for the work as a whole, including the study design, access to data, and the decision to submit and publish the manuscript. Charles Savona-Ventura researched the data and wrote the draft manuscript. Josanne Vassallo reviewed the data and edited the manuscript. The other members of the MGSD Educational Study Group were involved with the study design and reviewing the submitted manuscript.

List of Investigators. The MGSD-Education Study Group was composed of Prof. Charles Savona-Ventura-chairperson, Prof. Josanne Vassallo, Prof. Mohamed Khattab, Prof. Nebojsa Lalic, Prof. Stavros Liatis, Prof. Filipe Raposo, and Prof. Pedro Conthe.

Disclosures. Charles Savona-Ventura and Josanne Vassallo have nothing to disclose.

Compliance with Ethics Guidelines. Since the questionnaire was a self-administered one completed on a voluntary basis and not including any sensitive personal or identifiable information, the study was exempted from formal ethical approval by the University of Malta Research Ethics Committee.

Data Availability. The datasets during and/ or analyzed during the current study are available from the corresponding author on reasonable request.

Open Access. This article is distributed under the terms of the Creative Commons Attribution-NonCommercial 4.0 International License (http://creativecommons.org/licenses/ by-nc/4.0/), which permits any noncommercial use, distribution, and reproduction in any medium, provided you give appropriate credit to the original author(s) and the source, provide a link to the Creative Commons license, and indicate if changes were made.

\section{REFERENCES}

1. (G-I-N) The Guidelines International Network; 2018. http://www.g-i-n.net/about-g-i-n. Accessed 7 Apr 2018.

2. ADA. Standards in medical care in diabetes-2018. Diabetes Care. 2018;41(suppl. 1):S1-S159. http://care. diabetesjournals.org/content/41/Supplement_1.

3. RACGP. General practice management of type 2 diabetes 2016-2018. East Melbourne: Royal Australian College of General Practitioners; 2016. 
https://static.diabetesaustralia.com.au/s/fileassets/ diabetes-australia/5d3298b2-abf3-487e-9d5e-0558566 fc242.pdf.

4. Can J Diabetes. 2013;1(suppl. 1):S1-S212. http:// guidelines.diabetes.ca/app_themes/cdacpg/resourc es/cpg_2013_full_en.pdf.

5. ADA. Standards of medical care in diabetes-2018 abridged for primary care providers. Clin Diabetes. 2018;36(1):14-37. http://clinical.diabetesjournals. org/content/36/1/14.

6. Dent TH, Sadler M. From guidance to practice: why NICE is not enough. BMJ. 2002;324(7341):842-5.

7. Parsons JA, Yu CH, Baker NA, et al. Practice doesn't always make perfect: a qualitative study explaining why a trial of an educational toolkit did not improve quality of care. PLoS One. 2016;11(12):e0167878.

8. Hetlevik I, Holmen J, Midthjell K. Treatment of diabetes mellitus-physicians' adherence to clinical guidelines in Norway. Scand J Prim Health Care. 1997;15(4):193-219.
9. Ament SMC, de Groot JJA, Maessen JMC, Dirksen CD, van der Weijden T, Kleijnen J. Sustainability of professionals' adherence to clinical practice guidelines in medical care: a systematic review. BMJ Open. 2015;5:e008073.

10. Celeste-Harris S, Maryniuk M. Educating medical office staff: enhancing diabetes care in primary care offices. Diabetes Spectrum. 2006;19(2):84-9.

11. Harrison McDuffie R, Struck L, Burshell A. Empowerment for diabetes management: integrating true self-management into the medical treatment and management of diabetes mellitus. Ochsner J. 2001;3(3):149-57.

12. Powers MA, Bardsley J, Cypress M, et al. Diabetes self-management education and support in type 2 diabetes: a joint position statement of the American Diabetes Association, the American Association of Diabetes Educators, and the Academy of Nutrition and Dietetics. Diabetes Care. 2015;38(7):1372-82. 